\title{
PENGARUH JUMLAH TRAFFIC TERHADAP SITUATION AWARENESS PERSONEL PEMANDU LALU LINTAS UDARA DI PERUM LPPNPI CABANG TANJUNGPINANG
}

\author{
Putri Permata Ridayanti ${ }^{(1)}$, Rany Adiliawijaya P. ${ }^{(2)}$, Martha Saulina ${ }^{(3)}$ \\ 1,2,3 Politeknik Penerbangan Indonesia Curug \\ e-mail: ${ }^{1}$ putripermata247@gmail.com, ${ }^{2}$ rany.adiliawijaya@ppicurug.ac.id, \\ ${ }^{3}$ martha.saulina@ppicurug.ac.id
}

Abstrak: Penelitian ini bertujuan mengetahui pengaruh jumlah traffic terhadap situation awareness personel pemandu lalu lintas udara di Perum LPPNPI cabang Tanjungpinang. Metode penelitian yang digunakan adalah pendekatan kuantitatif dan teknik pengambilan data menggunakan studi dokumentasi dan kuesioner. Populasi yang digunakan ialah 52 personel pemandu lalu lintas udara di Approach Control Unit Tanjungpinang. Hasil penelitian menunjukan pengaruh positif dan searah antara jumlah traffic yang dikendalikan dengan situation awareness personel pemandu lalu lintas udara. Pengaruh positif menunjukan semakin rendah jumlah traffic yang dikendalikan maka semakin rendah tingkat situation awareness personel pemandu lalu lintas udara dan sebaliknya. Koefisien determinasi sebesar $36 \%$ sisanya dipengaruhi oleh faktor lain yang tidak diteliti. Persamaan regresi hasil penelitian ialah $\mathrm{Y}=20,451+0,570 \mathrm{X}$.

Kata Kunci: human factor, Pemandu Lalu Lintas Udara, situation awareness, Situation Awareness Rating Technique, traffic.

Abstract: $\quad$ The purpose of this research to know the effect of the amount of traffic in air traffic control personnel's situation awareness at Perum LPPNPI Tanjungpinang branch. The method used in this research is quantitative research and data collected used documentation and questionnare. As for the population in this research are 52 Air Traffic Controller personnels of Tanjungpinang Approach Control Unit. The result shows positive effect and parallel between the amount of traffic are controlled and air traffic controller's situation awareness. Positive effect shows decreasing the amount of traffic are controlled so air traffic controller's situation awareness will be decreasing and vice versa. Determination coefficient is $36 \%$ and the rest is determined by the other factors. The regression equation test is $\mathrm{Y}=20,451+0,570 \mathrm{X}$.

http://journal.ppicurug.ac.id/index.php/jurnal-langit-biru 
Langit Biru: Jurnal Ilmiah Aviasi Vol. 14 No. 1 Februari 2021

ISSN (p) 1979-1534 ISSN (e) 2745-8695

Keyword: human factor, Air Traffic Controller, situation awareness, Situation Awareness Rating Technique, traffic.

\section{Pendahuluan}

Salah satu personel yang berperan penting dalam pemberian pelayanan navigasi penerbangan ialah pemandu lalu lintas udara. Semua aktifitas dan pergerakan pesawat diharuskan mendapat informasi (information), instruksi (instruction) dan izin (clearance) dari pemandu lalu lintas udara sehingga tercapainya tujuan keselamatan penerbangan. Pemandu lalu lintas udara memiliki 5 tujuan pelayanan dengan istilah five objective of Air Traffic Services yang terdapat dalam dokumen ICAO Annex 11, $15^{\text {th }}$ Edition (2018) dimana salah satu tujuan pelayanan pemandu lalu lintas udara ialah mencegah tabrakan antar pesawat.

Pada nyatanya, tingkat kecelakan pesawat terus bertambah. Berdasarkan Media Release KNKT tahun 2017, kecelakaan yang terjadi memiliki penyebab terbesar yaitu human factor sebesar $67.52 \%$. Adapun Breakdown of Separation (BOS) yang terjadi di Approach Control Unit Tanjungpinang pada tanggal 31 Agustus 2018, yaitu terjadi BOS antara LNI272 (Boeing739) dengan PK-OCK (DHC6) yang berangkat dari Bandar Udara Hang Nadim Batam. Saat itu PK-OCK sebagai pesawat pertama dan LNI272 sebagai pesawat kedua meminta departure clearance kepada Tanjungpinang Approach. Lalu Tanjungpinang Approach berkoordinasi dengan Singapore Director terkait departure clearance karena
Tanjungpinang Approach hanya memiliki upper limit 3000 feet di area tersebut. Setelah itu Tanjungpinang Approach meneruskan departure clearance yang didapat kepada kedua traffic tersebut dan memberikan izin lepas landas untuk pesawat pertama (PK-OCK). Beberapa menit setelahnya Tanjungpinang Approach mengganti departure clearance pesawat kedua (LNI272) untuk contact ke Tanjungpinang Approach terlebih dahulu agar dapat memisahkan traffic. Lalu LNI272 diberikan izin lepas landas, dan tidak lama setelah itu pilot bertanya apakah ada traffic dengan ketinggian yang sama (PK-OCK) dan terjadilah Breakdown of Separation. Saat sadar LNI272 mendekati PK-OCK, Tanjungpinang Approach langsung memberikan LNI272 instruksi untuk turning left menjauhi PK-OCK.

Personel pemandu lalu lintas udara sering dihadapkan pada kondisi pekerjaan yang mengharuskan kecepatan dalam pengambilan keputusan, namun pemandu lalu lintas udara bisa saja melakukan kesalahan akibat hilangnya kemampuannya untuk tetap waspada terhadap segala hal yang terjadi pada waktu bersamaan dan kemudian mengintegrasikannya dalam tindakan saat itu, ini disebut dengan situation awareness (Haines \& Flateau, 1992).

Dari Jurnal Situation Awareness Synthesis of Literature Search (2000), kehilangan kewaspadaan dilaporkan sebagai salah satu resiko terbesar bagi 
Pengaruh Jumlah Traffic Terhadap Situation Awareness Personel Pemandu Lalu Lintas Udara di Perum LPPNPI Cabang Tanjungpinang

pemandu lalu lintas udara karena merupakan sumber dari beberapa resiko seperti:

1. Tidak dapat memprediksi perkembangan situasi,

2. Gagal mendeteksi - lebih awal masalah atau konflik,

3. Tidak dapat memberikan keputusan secara optimal, dan

4. Dalam kasus yang ekstrim, memungkinkan terciptanya incidents / accidents.

Menurut Jurnal Development of

Situation Awareness Measures in ATM

System (2003), salah satu faktor yang menyebabkan hilangnya situation awareness adalah volume of traffic; unexpected and sudden variation of traffic load atau jika diterjemahkan secara bebas adalah volume dari arus lalu lintas. Adapun berikut data traffic yang dikendalikan oleh personel pemandu lalu lintas udara di Perum LPPNPI Cabang Tanjungpinang selama 24 jam pengoperasian;

Tabel 1. Jumlah Traffic di Approach Control Unit Tanjungpinan

\begin{tabular}{|c|c|}
\hline Tanggal \& Bulan (2020) & Jumlah Traffic \\
\hline 1 Agustus & 49 \\
\hline 2 Agustus & 53 \\
\hline 3 Agustus & 64 \\
\hline 4 Agustus & 62 \\
\hline 5 Agustus & 57 \\
\hline 6 Agustus & 50 \\
\hline 7 Agustus & 59 \\
\hline 8 Agustus & 50 \\
\hline 9 Agustus & 55 \\
\hline 10 Agustus & 68 \\
\hline
\end{tabular}

Sejalan juga dengan ICAO Doc. 9806 Human Faktor Guidelines For Safety Audit Manual $1^{\text {th }}$ Edition (2002); seorang pemandu lalu lintas udara sering melakukan kesalahan dimana kewaspadaan seorang pemandu lalu lintas berkurang yaitu saat:

1. Under light to moderate traffic conditions and complexity;

2. During a controller's first fifteen minutes on position; and

3. When controllers have less than six years' experience.

Berdasarkan dokumen diatas, pada poin satu menunjukan bahwa adanya hubungan antara berkurangnya kewaspadaan (awareness) dengan kondisi traffic yang dikendalikan.

Situation awareness merupakan elemen penting dalam keselamatan penerbangan sehingga pemandu lalu lintas udara harus mempertahankan situation awareness sesuai dengan Doc. 9806 Human Faktor Guidelines For Safety Audit Manual $1^{\text {th }}$ Edition (2002): "7.4.27 Maintaining the mental picture is so important to controllers that a few more words about situational awareness from the perspective of the controller are war-ranted. Situational awareness may be considered from three levels of cognition: perceiving the situation, comprehending the significance of the situation and finally, projecting the situation into the future to make effective plans for dealing with the situation."

\section{Metode}

Metode penelitian yang digunakan ialah penelitian kuantitatif. Populasi yang digunakan ialah 52 personel pemandu lalu lintas udara di Approach Control Unit Tanjungpinang. Teknik sampling yang digunakan ialah random sampling berjumlah 46 orang. Metode 
Langit Biru: Jurnal Ilmiah Aviasi Vol. 14 No. 1 Februari 2021

ISSN (p) 1979-1534 ISSN (e) 2745-8695

pengumpulan data menggunakan studi dokumentasi dan kuesioner. Metode analisis data menggunakan uji normalitas (asumsi dasar) uji korelasi, determinasi dan analisis regrisi (analisis hubungan).

\section{Metode Pengumpulan Data}

Pada penelitian ini variabel $\mathrm{X}$ (jumlah traffic) diukur berdasarkan data penerbangan (traffic) harian di Approach Control Unit Tanjungpinang. Sedangkan vaiabel Y (Situation Awareness) diukur menggunakan metode SART (Situation Awareness Rating Technique).

Tabel 2. Dimensi dan Indikator pengukuran variabel Y (Situation Awareness)

\begin{tabular}{|c|c|c|}
\hline No. & Dimensi & Indikator \\
\hline 1. & $\begin{array}{l}\text { Attention } \\
\text { Demand (D) }\end{array}$ & $\begin{array}{l}\text { - Instability of } \\
\text { situation } \\
\text { - Variability of } \\
\text { situation } \\
\text { - Complexity of } \\
\text { situation }\end{array}$ \\
\hline 2. & $\begin{array}{l}\text { Attention Supply } \\
\text { (S) }\end{array}$ & $\begin{array}{ll}\text { - } & \text { Arousal } \\
\text { - } & \text { care mental } \\
& \text { capacity } \\
\text { - } & \text { Concentration } \\
\text { - } & \text { Division of } \\
\text { attention }\end{array}$ \\
\hline 3. & $\begin{array}{l}\text { Understanding } \\
\text { (U) }\end{array}$ & $\begin{array}{l}\text { - Information } \\
\text { quality } \\
\text { - Information } \\
\text { quantity } \\
\text { - Familiarity }\end{array}$ \\
\hline & Metode & (Situation \\
\hline $\begin{array}{l}A w \\
\text { mei } \\
\text { awe } \\
\text { pen } \\
\text { Tay } \\
\text { uji }\end{array}$ & $\begin{array}{l}\text { eness Rati } \\
\text { oakan alat } \\
\text { eness berupa } \mathrm{k} \\
\text { bangan yang } \mathrm{c} \\
\text { r pada tahun } 1 \\
\text { liditas dan relia }\end{array}$ & $\begin{array}{l}\text { Technique) } \\
\text { ukur situation } \\
\text { sioner di bidang } \\
\text { embangkan oleh } \\
0 \text { dan dilakukan } \\
\text { litas (Jeannot, E, }\end{array}$ \\
\hline
\end{tabular}

2000). Kemudian perhitungannya menggunakan rumus:

$$
\mathbf{S A}=\mathbf{U}-(\mathbf{D}-\mathbf{S})
$$

\section{Metode Analisis Data}

Berikut metode analisis data yang digunakan pada penelitian ini:

1. Uji asumsi dasar menggunakan uji normalitas, uji tersebut dilakukan sebelum penerapan suatu rumus statistik untuk pengujian hipotesis untuk mengetahui apakah data suatu penelitian berdistribusi normal atau tidak. Dalam penelitian ini penulis menggunakan rumus uji normalitas Liliefors.

2. Analisis hubungan menggunakan uji korelasi Spearman Rank untuk menghitung seberapa besar hubungan kedua variabel selanjutnya membuktikan hipotesis menggunakan uji hipotesis $\mathrm{T}$. Kemudian koefisien determinasi untuk menghitung besar pengaruh dan selanjutnya analisis regresi sederhana.

\section{Diskusi}

Diambil data sekunder dengan studi dokumentasi berupa jumlah traffic yang dikendalikan oleh responden di hari yang sama saat responden mengisi angket atau kuesioner situation awareness yang dialami saat jam control. Didapati hasil responden mendapat 5-14 traffic dalam waktu pengontrolan 1-2 jam.

Berdasarkan hasil perhitungan yang telah dilakukan pada hasil kuesioner variabel (Y) situation awareness diperoleh nilai rata-rata 58,47 . 
Pengaruh Jumlah Traffic Terhadap Situation Awareness Personel Pemandu Lalu Lintas Udara di Perum LPPNPI Cabang Tanjungpinang

Sesuai tabel di bawah, maka situation awareness personel pemandu lalu lintas udara di Approach Control Unit Tanjungpinang hanya tergolong cukup.

Tabel 3. Tabel Ukur Situation Awareness

\begin{tabular}{|c|c|}
\hline Pernyataan & Skor \\
\hline Sangat Rendah & $1-19$ \\
\hline Rendah & $20-39$ \\
\hline Cukup & $40-59$ \\
\hline Tinggi & $60-79$ \\
\hline Sangat Tinggi & $80-100$ \\
\hline
\end{tabular}

Berikut hasil analisis pengolahan data sesuai metode analisis data

1. Uji asumsi dasar

Menggunakan uji normalitas Liliefors, dikatakan berdistribusi normal jika $|\mathrm{F}(\mathrm{Z})-\mathrm{S}(\mathrm{Z})|\left(\mathrm{L}_{\mathrm{o}}\right)$ masing - masing variabel harus lebih kecil dari nilai kritis tabel Liliefors $\left(\mathrm{L}_{\mathrm{t}}\right)$ untuk 46 responden dengan taraf kesalahan 5\%. Pada tabel 4 dan 5 merupakan perbandingan nilai pada uji normalitas.

Tabel 4. Hasil uji normalitas data variabel X (jumlah traffic)

\begin{tabular}{|c|c|}
\hline $\mathrm{L}_{\mathrm{o}}$ & $\mathrm{L}_{\mathrm{t}}$ \\
\hline 0,115 & 0,131 \\
\hline
\end{tabular}

Tabel 5. Hasil uji normalitas data variabel Y (situation awareness)

\begin{tabular}{|c|c|}
\hline Lo $_{\mathrm{o}}$ & $\mathrm{L}_{\mathrm{t}}$ \\
\hline 0,118 & 0,131 \\
\hline
\end{tabular}

Dapat disimpulkan bahwa data variabel $\mathrm{X}$ dan $\mathrm{Y}$ berdistribusi normal.

2. Analisis Hubungan

Uji ini menggunakan uji korelasi, koefisien determinasi dan analisis regresi. Pada uji korelasi menggunakan Spearman Rank, didapati koefisien korelasi (r) penelitian ini sebesar 0,601 . Nilai 0,601 menunujukan hubungan yang kuat sesuai tabel interprestasi koefisien korelasi pada tabel 6 dan nilai yang positif memiliki arti hubungan yang searah.

Tabel 6. Tabel interprestasi hubungan.

\begin{tabular}{|c|c|}
\hline INTERVAL & TINGKAT \\
\hline $0,00-0,199$ & Sangat rendah \\
\hline $0,20-0,399$ & Rendah \\
\hline $0,40-0,599$ & Sedang \\
\hline $0,60-0,799$ & Kuat \\
\hline $0,80-1,00$ & Sangat kuat \\
\hline
\end{tabular}

Selanjutnya pembuktian hipotesis statistik pengaruh kedua variabel menggunakan uji hipotesis $\mathrm{T}$, yaitu dengan melakukan perbandingan antara nilai $t_{\text {hitung }}$ dan $t_{\text {tabel }}$. Apabila $t_{\text {hitung }}>t_{\text {tabel }}$ maka hipotesis diterima, dan sebaliknya. Didapati $t_{\text {hitung }}(4,988)>t_{\text {tabel }}$ $(2,013)$ maka hipotesis bahwa terdapat hubungan yang positif dan signifikan antara jumlah traffic dan situation awareness diterima.

Didapati nilai koefisien determinasi untuk menunjukan kontribusi jumlah traffic terhadap situation awareness personel pemandu lalu lintas udara sebesar 36\%, selebihnya dipengerahui faktor lain yang tidak diteliti pada penelitian ini.

Analisis regresi sederhana pada penelitian ini adalah $\mathrm{Y}=20,451+$ $0,570 X$. Nilai b $(+0,570)$ yang memiliki tanda positif mengartikan hubungan yang searah, apabila variabel $\mathrm{X}$ menurun maka variabel $\mathrm{Y}$ juga menurun, begitupun sebaliknya. Dengan demikian, apabila jumlah traffic mengalami penurunan 1 poin maka 
situation awareness personel pemandu lalu lintas udara di Approach Control Unit Tanjungpinang juga mengalami penurunan sebesar 0,570 pada konstanta 20,451 dan juga sebaliknya.

\section{Kesimpulan}

Kesimpulan pada penelitian sebagai berikut:

1. Tingkat situation awareness personel pemandu lalu lintas udara di Approach Control Unit Tanjungpinang berdasarkan perhitungan menggunakan kuesioner Situation Awareness Rating Technique (SART) mendapatkan nilai rata-rata 58,47 yang berarti situation awareness personel pemandu lalu lintas udara di Approach Control Unit Tanjungpinang termasuk dalam kategori cukup.

2. Jumlah traffic di Approach Control Unit Tanjungpinang mempunyai pengaruh yang kuat dan signifikan terhadap situation awareness personel pemandu lalu lintas udara dengan koefisien korelasi 0,601. Koefisien korelasi yang bernilai 0,601 menunjukan bahwa hubungan antar variabel positif dan searah. Korelasi positif menandakan bahwa semakin tinggi jumlah traffic yang dikendalikan maka semakin tinggi pula tingkat situation awareness yang didapat dan semakin rendah jumlah traffic yang dikendalikan maka semakin rendah pula tingkat situation awareness yang didapat. Kontribusi jumlah traffic yang dikendalikan terhadap situation awareness personel pemandu lalu lintas udara adalah sebesar $36 \%$ dan sisanya dipengaruhi oleh faktor lain yang tidak diteliti pada penelitian ini. Hubungan fungsional antara jumlah traffic terhadap situation awareness personel pemandu lalu lintas udara adalah $\mathrm{Y}=20,451+0,570 \mathrm{X}$. Dapat diartikan bahwa setiap perubahan variabel independen $X=$ jumlah traffic yang dikendalikan akan berdampak berubahnya variabel $\mathrm{Y}$ $=$ situation awareness, apabila jumlah traffic mengalami penurunan 1 poin maka situation awareness personel pemandu lalu lintas udara di Approach Control Unit Tanjungpinang juga mengalami penurunan sebesar 0,570 pada konstanta 20,451 dan juga sebaliknya.

\section{Daftar Pustaka}

Aminarno, B.P., Drs., S.SiT., MM., (2019). Metode Penelitian Ilmiah. Curug: Politeknik Penerbangan Indonesia.

Rafi Rullyant C., S.Tr., (2018). Analisis Pengaruh Perhatian Terhadap Situation Awareness Pada Pemandu Lalu Lintas Udara di Unit Approach Control Jakarta Air Traffic Service Center. Curug: Sekolah Tinggi Penerbangan Indonesia.

Data Breakdown Of Separation (2018). Perum LPPNPI Cabang Tanjungpinang: Approach Control Unit.

Endsley, Mica R, (2016). Situation Awareness Measurement in Test and Evaluation. Lubbock: Research Gate. 
Pengaruh Jumlah Traffic Terhadap Situation Awareness Personel Pemandu Lalu Lintas Udara di Perum LPPNPI Cabang Tanjungpinang

International Civil Aviation Organization (2018). Annex 11, Air Traffic Service $15^{\text {th }}$ Edition. Montreal: Secretary General.

International Civil Aviation Organization (2002). Doc. 9806 AN/763, Human Factor Guidelines For Safety Audit Manual $1^{\text {th }}$ Edition. Montreal: Secretary General.

Jeannot, Emmanuelle, Christopher Kelly (2003). The Development of Situation Awareness Measures in ATM Systems. Paris: Eurocontrol Agency.

Jeannot, E (2000). Situation Awareness Synthesis Of Literature Search, Paris: Eurocontrol Agency. 